\section{The diet and presence of African wild dogs (Lycaon pictus) on private land in the Waterberg region, South Africa}

\author{
Rivona Ramnanan', Lourens H. Swanepoel ${ }^{1 *}$ \\ \& Michael J. Somers ${ }^{1,2}$ \\ ${ }^{1}$ Centre for Wildlife Management, University of Pretoria, \\ Private Bag X20, Hatfield, Pretoria, 0028 South Africa \\ ${ }^{2}$ Centre for Invasion Biology, University of Pretoria, \\ Private Bag X20, Hatfield, Pretoria, 0028 South Africa \\ Received 29 June 2012. Accepted 23 February 2013
}

African wild dog (Lycaon pictus) populations and their geographic distributions have been greatly reduced due to direct human persecution and habitat reduction; however, remnant groups still manage to persist on private reserves and farmland. Farmland, especially game farming areas, can potentially be suitable for wild dog conservation. However, little is known about them in these areas. To increase our understanding regarding the presence and general ecology of wild dogs on private land we used a camera trapping picture database initially used to census leopards (Panthera pardus) to report on wild dog presence on private farmland and reserves within the Waterberg Biosphere, South Africa. We identified nine different wild dogs from the camera trap images and all wild dog signs were restricted to Lapalala. We further supplemented the data set with opportunistically collected scats to report on wild dog prey use. Only three species could be identified in the scats, namely bushbuck (Tragelaphus scriptus), impala (Aepyceros melampus) and greater kudu (Tragelaphus strepsiceros), with bushbuck the most important prey species. Our results show that some wild dogs still persist on private land in the Waterberg, confirming that private land can play an important role in wold dog conservation. We suggest that conservation efforts focussing on mitigation actions to improve local tolerance towards wild dogs would be the most efficient action to secure a viable wild dog population.

Key words: non-invasive survey, large carnivores, wildlife monitoring, camera trapping, scat analysis.

*To whom correspondence should be addressed. E-mail: lourens.swanepoel@up.ac.za

\section{INTRODUCTION}

The African wild dog (Lycaon pictus) was once widely distributed across most of sub-Saharan Africa (Creel \& Creel 2002). However, wild dog populations and their geographic distribution have been greatly reduced due to direct human persecution and habitat reduction (Woodroffe et al. 2004, 2007) and are therefore listed as endangered throughout their range (Friedmann \& Daly 2004; Woodroffe \& Sillero-Zubiri 2012). In South Africa they are restricted to protected areas and private game farms (Lindsey et al. 2004) with the only viable population in the Kruger National Park. Many, but not all of the wild dogs in the smaller protected areas, form part of a growing managed meta-population (consisting of a number of sub-populations; Akçakaya et al. 2007) spread across South Africa (Gusset et al. 2008a; DaviesMostert et al. 2009). However, remnant wild dog groups still persist on agricultural farms and private protected areas in South Africa (Lindsey et al. 2005a). Farmland therefore, especially game farming areas, can potentially be important for wild dog conservation efforts (Lindsey et al. 2005a,b). However, conservation efforts on private land have been limited by conflict with landowners and little is known about their distribution (Lindsey et al.2004; 2005a) and ecology in these areas.

To increase our understanding of the distribution and diet of wild dogs on private land we used a camera trapping picture database initially used to census leopards (Panthera pardus) to report on wild dog presence on private farmland and reserves within the Waterberg Biosphere, South Africa. We further supplemented the data set with opportunistically collected scats to determine their diet in this area.

\section{METHODS}

\section{Study site}

The study was conducted at four sites in the

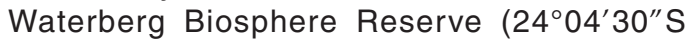
$28^{\circ} 08^{\prime} 30^{\prime \prime} E$ ), Limpopo Province, South Africa (Fig. 1.). Welgevonden Private Game Reserve $\left(375 \mathrm{~km}^{2}\right)$ is a syndicated reserve that is dedicated to conservation and ecotourism, Lapalala Wilderness (hereafter Lapalala; $360 \mathrm{~km}^{2}$ ) is a privately owned game reserve dedicated to conservation 


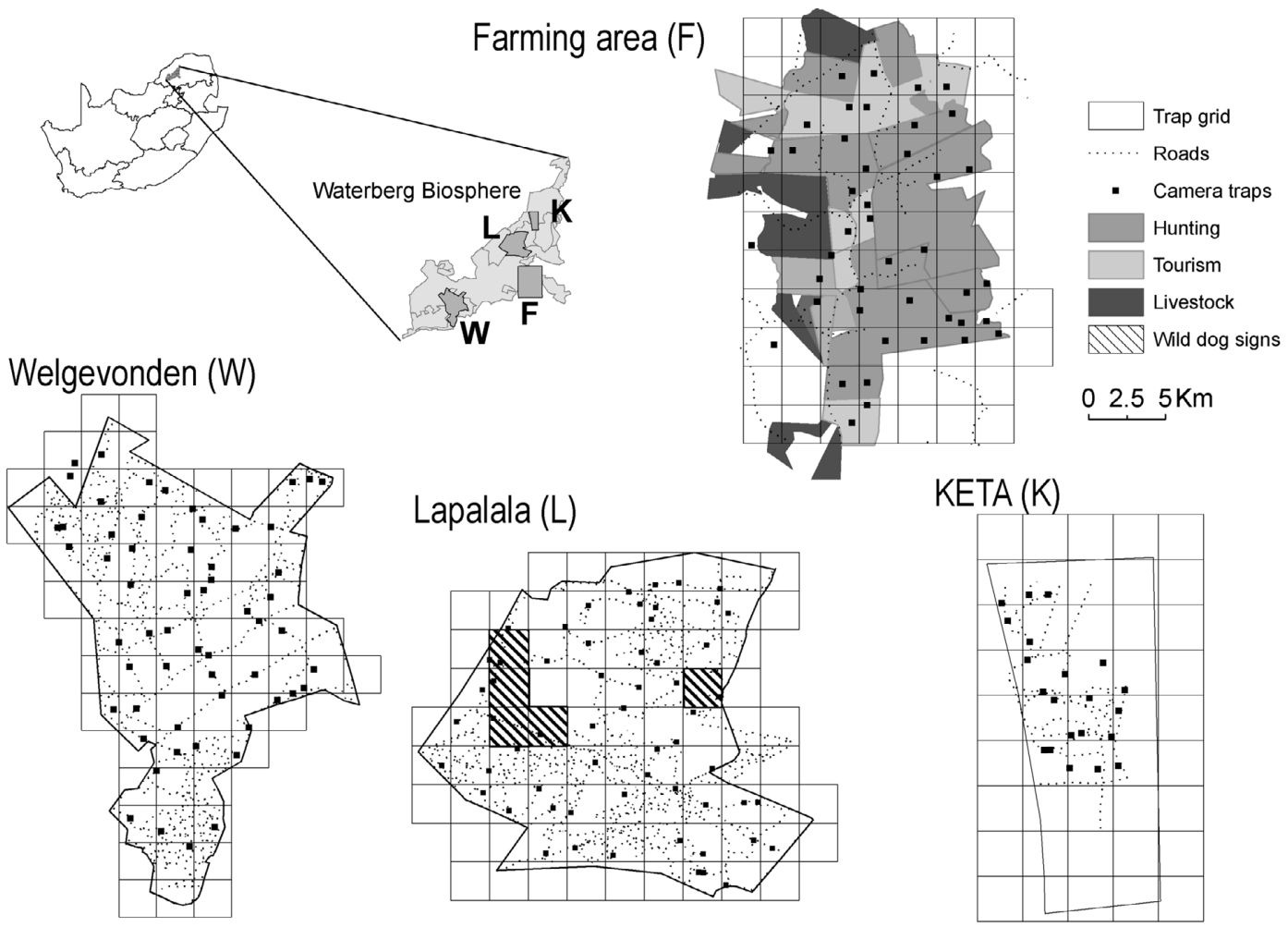

Fig. 1. Study area and wild dog presence as detected by camera traps and scats collected in the Waterberg Biosphere, South Africa during 2008-2010. Welgevonden and Lapalala are dedicated to conservation and KETA game farm to trophy hunting and breeding of rare ungulates.

and environmental education and KETA game farm $\left(150 \mathrm{~km}^{2}\right)$ is a commercial game farm dedicated to trophy hunting and breeding of rare ungulates. The remaining site of $350 \mathrm{~km}^{2}$ was a mixed farming area which consisted of eight hunting game farms, 11 livestock farms and seven farms focussing on ecotourism (Fig. 1). The vegetation in the area is classified as Waterberg Mountain Bushveld (Mucina \& Rutherford 2006) and all the study sites were characterized by rugged mountainous terrain.

\section{Camera trapping}

Initial camera trapping studies in 2008 were conducted during the wet season (November and December) whereas subsequent camera trapping surveys in 2009 and 2010 were conducted in the dry season (May-August). We followed established camera trapping protocols (Karanth 1995) where we divided study sites into the following number of $2.5 \mathrm{~km} \times 2.5 \mathrm{~km}$ grids; Welgevonden (62 grids, 2008/2009/2010), Lapalala (60 grids, 2008/2009/2010), KETA (30 grids, 2008) and farming area (45 grids, 2009). Camera trapping surveys thus covered $950 \mathrm{~km}^{2}$ (2008), $1043 \mathrm{~km}^{2}$ (2009) and $762 \mathrm{~km}^{2}$ (2010). Due to a limited number of camera traps we surveyed 15 grids at each site before we moved the traps to the next 15 grids (Karanth 1995). At Welgevonden and KETA we used Moultrie 140 (Moultrie Feeders, Inc., Alabaster, $A L$ ) infrared digital camera traps, and at Lapalala and the farm area a combination of Moultrie and flash film camera traps (Trailmasters ${ }^{\circledR}$ TM 1550, Goodson Associates Inc., Lenexa, KS, U.S.A.; DeerCam DC100, Non Typical Inc., Wisconsin, U.S.A.; Stealth Cam MC2-GV, Stealth Cam, Grand Prairie, U.S.A.). We used a one-minute delay on digital and 10 min delay on film camera traps, and we used lures (fish and rotten egg mix) at all sites since digital camera traps had slow trigger speeds. Cameras were checked every fourth day to change film and refresh lures. All camera traps images were stored in a camera trapping picture database (Tobler 2007).

We extracted all wild dog images from the camera trapping database to identify individual dogs using 
Table 1. Wild dog diet at Lapalala in the Waterberg Biosphere, South Africa, as determined by scat analysis.

\begin{tabular}{lccc}
\hline & \multicolumn{3}{c}{ Total $^{\mathrm{a}}$} \\
\cline { 2 - 4 } $\begin{array}{l}\text { Prey } \\
\text { occurrence }\end{array}$ & $\begin{array}{c}\text { Count of } \\
\text { occurrence }\end{array}$ & $\begin{array}{c}\text { Frequency of } \\
\text { consumed (\%) }\end{array}$ & Relative biomass \\
\hline $\begin{array}{l}\text { Bushbuck } \\
\text { (Tragelaphus scriptus) }\end{array}$ & 44 & 93.4 & 31.9 \\
$\begin{array}{l}\text { Greater kudu } \\
\text { (Tragelaphus strepsiceros) }\end{array}$ & 4 & 8.5 & 9.0 \\
$\begin{array}{l}\text { Impala } \\
\text { (Aepyceros melampus) }\end{array}$ & 9 & 19.1 & 6.3 \\
Total & 57 & 121 & \\
\hline
\end{tabular}

${ }^{a} 47$ scats, consisting of 57 prey items (1.2 items/scat).

their characteristic individual markings (Somers et al. 2008). We used the GPS locations of wild dog images and collected scats to map the presence of wild dogs in the surveyed areas. We also calculated the number of images per 100 camera trap nights for other carnivores at each site to evaluate the effectiveness of the camera trapping for detecting carnivores.

\section{Scat analysis}

The wild dog scats were collected opportunistically along the roadside when setting up and checking camera traps. Scats were identified by experts based on the size, shape, odour and associated wild dogs tracks. Scats were normally found early morning in large numbers on roads. Collected scats were geo-referenced and stored in Ziplock bags for later analysis. Scats were dried and then washed in a $1.5 \mathrm{~mm}$ sieve to separate hair, bone fragments and vegetation. We then cleaned undigested hair with alcohol and sulphuric acid. Twenty hair strands where randomly selected from each cleaned hair sample to make cuticular imprints and cross-sections (Keogh 1983; Ramakrishnan et al. 1999). We identified prey items by comparing the cross sections and cuticular imparts to published reference keys (Perrin \& Campbell 1980; Keogh 1983) and a reference collection housed at the Centre for Wildlife Management. Scat analysis results were converted to count of occurrence and frequency of occurrence (Mbizah et al. 2012). We assumed that the digestion rate of dhole (Cuon alpinus) is similar to wild dogs, so we used to the linear regression $(Y=1.98+0.020 X)$, to relate live weight of prey $(X)$ consumed to relative biomass consumed (Karanth \& Sunquist 1995). The live weights of the prey animals were calculated using three fourths of the mean adult female body mass to account for predation of juveniles (Hayward et al. 2006).

\section{RESULTS}

\section{Scats analysis}

A total of 47 scats was collected at 14 scat clusters (3.4 scats/cluster), which yielded 57 different prey items (1.2 prey items/scat). Only three species could be identified in the scats; bushbuck (Tragelaphus scriptus), impala (Aepyceros melampus) and greater kudu (Tragelaphus strepsiceros; Table 1). Bushbuck was by far the most important prey species, both in terms of occurrence and biomass (Table 1). The weight for wild dog prey in the study area varied between $23 \mathrm{~kg}$ and $135 \mathrm{~kg}$. Although we lacked prey data for the survey periods, aerial counts conducted during 2007 at Lapalala reported 76 bushbuck, 597 greater kudu and 922 impala.

\section{Camera trapping}

During a trapping effort of 4060 trap days we recorded 9241 independent images of animals and humans, which consisted of 2943 images of humans, 3604 images of prey animals and 2694 carnivore images. We only obtained 20 wild dog images $(0.2 \%$ of total) which were restricted to Lapalala (Fig. 1). Wild dog signs (images or scats) were only detected in five out of a possible $197 \mathrm{grid}$ sites (Fig. 1). Due to the limited number of images and poor quality we could not uniquely identify all wild dogs. At most we could positively identify nine individuals; however, in 2008, one picture contained 15 dogs. There was a difference in the spectrum of carnivores photographed at each site (Table 2). Wild dogs were only detected al Lapalala while lions and cheetah were restricted to 
Table 2. Carnivore species photographed (number of images/100 trap days) during a camera trapping survey in the Waterberg Biosphere, South Africa, based on an effort of 1606 trap days for Welgevonden, 1374 for Lapalala, 240 for KETA and 840 for the farming area.

\begin{tabular}{|c|c|c|c|c|}
\hline & $\begin{array}{l}\text { Welgevonden } \\
(2008-2010)\end{array}$ & $\begin{array}{c}\text { Lapalala } \\
(2008-2010)\end{array}$ & $\begin{array}{l}\text { KETA } \\
(2008)\end{array}$ & $\begin{array}{c}\text { Farming area } \\
\text { (2009) }\end{array}$ \\
\hline $\begin{array}{l}\text { African civet } \\
\text { (Civettictis civetta) }\end{array}$ & 17.83 & 14.95 & 4.17 & 18.81 \\
\hline $\begin{array}{l}\text { Blacked-back jackal } \\
\text { (Canis mesomelas) }\end{array}$ & 7.02 & 2.93 & 7.50 & 4.02 \\
\hline $\begin{array}{l}\text { Brown hyaena } \\
\text { (Hyaena brunnea) }\end{array}$ & 20.83 & 12.63 & 5.83 & 4.26 \\
\hline $\begin{array}{l}\text { Leopard } \\
\text { (Panthera pardus) }\end{array}$ & 3.54 & 3.00 & 3.33 & 2.95 \\
\hline $\begin{array}{l}\text { Lion } \\
\text { (Panthera leo) }\end{array}$ & 2.30 & 0.00 & 0.00 & 0.00 \\
\hline $\begin{array}{l}\text { Honey badger } \\
\text { (Mellivora capensis) }\end{array}$ & 2.42 & 0.90 & 0.83 & 4.06 \\
\hline $\begin{array}{l}\text { Serval } \\
\text { (Leptailurus serval) }\end{array}$ & 1.61 & 0.00 & 0.00 & 0.23 \\
\hline $\begin{array}{l}\text { Spotted hyaena } \\
\text { (Crocuta crocuta) }\end{array}$ & 1.25 & 0.09 & 0.00 & 0.00 \\
\hline $\begin{array}{l}\text { Caracal } \\
\text { (Caracal caracal) }\end{array}$ & 2.55 & 1.30 & 0.00 & 1.61 \\
\hline $\begin{array}{l}\text { Slender mongoose } \\
\text { (Galerella sanguinea) }\end{array}$ & 0.84 & 0.64 & 0.00 & 2.49 \\
\hline $\begin{array}{l}\text { Large-spotted genet } \\
\text { (Genetta tigrina) }\end{array}$ & 1.05 & 3.84 & 0.83 & 2.32 \\
\hline $\begin{array}{l}\text { White tailed mongoose } \\
\text { (Ichneumia albicauda) }\end{array}$ & 0.38 & 0.21 & 0.42 & 0.36 \\
\hline $\begin{array}{l}\text { Small-spotted genet } \\
\text { (Genetta genetta) }\end{array}$ & 1.08 & 0.36 & 0.00 & 0.00 \\
\hline $\begin{array}{l}\text { African wildcat } \\
\text { (Felis silvestris lybica) }\end{array}$ & 0.63 & 0.59 & 2.08 & 0.48 \\
\hline $\begin{array}{l}\text { Cheetah } \\
\text { (Acinonyx jubatus) }\end{array}$ & 0.17 & 0.00 & 0.00 & 0.00 \\
\hline $\begin{array}{l}\text { Banded mongoose } \\
\text { (Mungos mungo) }\end{array}$ & 0.08 & 1.45 & 0.83 & 0.57 \\
\hline $\begin{array}{l}\text { Aardwolf } \\
\text { (Proteles cristata) }\end{array}$ & 0.00 & 0.12 & 0.42 & 0.00 \\
\hline $\begin{array}{l}\text { Bat eared fox } \\
\text { (Otocyon megalotis) }\end{array}$ & 0.26 & 0.00 & 0.00 & 0.00 \\
\hline $\begin{array}{l}\text { Striped polecat } \\
\text { (Ictonyx striatus) }\end{array}$ & 0.00 & 0.00 & 0.00 & 0.12 \\
\hline $\begin{array}{l}\text { Water mongoose } \\
\text { (Atilax paludinosus) }\end{array}$ & 0.00 & 0.16 & 0.00 & 1.19 \\
\hline $\begin{array}{l}\text { Wild dog } \\
\text { (Lycaon pictus) }\end{array}$ & 0.00 & 0.73 & 0.00 & 0.00 \\
\hline
\end{tabular}

Welgevonden. The rest of the carnivore spectrum was fairly evenly detected among study sites (Table 2).

\section{DISCUSSION}

Wild dogs in South Africa are a conservationdependent species and any data on their distribution and ecology will advance conservation efforts.
Our results here contribute to the few data on wild dogs on private land that does not currently form part of the managed meta-population (Lindsey et al. 2004, 2005a). Our dietary analyses concur with previous results that wild dogs mainly prey on greater kudu, impala and bushbuck (Hayward et al. 2006; Mbizah et al. 2012), and bushbuck was mostly consumed in our study. Although we 
acknowledge that we did not calculate prey selection or preference given the limited prey numbers available, it also appears that wild dogs in Lapalala preferred bushbuck.

The prey consumed by wild dogs in Lapalala ranged between $23 \mathrm{~kg}$ and $135 \mathrm{~kg}$, which concur with various other studies (Creel \& Creel 1995; Mbizah et al. 2012). Wild dogs seem to specialize on medium-sized ungulates $(15-100 \mathrm{~kg}$; Creel \& Creel 1995) and since we used $3 / 4$ the adult mass of prey, we could have overestimated their contribution to the wild dog diet. This is because studies have shown that a proportion of wild dog prey include juveniles of prey species (e.g. Pole et al. 2006). We also acknowledge that our limited number of scats collected, short sampling period and the linear regression not specifically developed for wild dogs could have biased our dietary results. A longer sampling period and a larger sample of scats will probably increase the accuracy; nevertheless, our limited results here suggest that wild dogs prey on their predicted prey species (Hayward et al. 2006). Furthermore, similar to most studies on wild dog diet no livestock remains were found in any scats, suggesting they seldom prey on livestock (Woodroffe et al. 2005). However, our scat data were limited to a conservation area in our study area which could have biased our prey data.

Camera traps are useful for studying uncommon animals that are not easily seen (Treves et al. 2010). Our results confirm this notion and the existing camera trap database detected most carnivore species across all study sites (Table 2). In keeping with other studies our results suggests that farming areas still maintain a rich carnivore assemblage, although wide-ranging carnivores (e.g. lions, cheetah, wild dogs) are restricted to large private protected areas (Lindsey et al. 2013; Lindsey et al. 2005a). Wild dog signs (images or scats) were only detected in Lapalala, which suggests that wild dogs are not common in the area. Given that from our camera trap images we detected a maximum of 15 dogs we speculate that at least one viable pack exists in the study area. The presence of a pack of 25 in the area was confirmed (Anton Walker, personal communication). However, wild dog pack size can fluctuate widely over a year due to high pup morality rates (Creel \& Creel 2002), which can affect the number of dogs detected by cameras and people. Furthermore, we must highlight that wild dogs have large home ranges (Creel \& Creel 2002; Woodroffe et al. 2005), and because camera traps detect species with small home ranges more frequently (Treves et al. 2010), our camera trapping protocol could have missed some wild dogs. We also had to move camera traps between sites which could have resulted in missed detection. Lastly, some of our camera trapping surveys were limited to the dry season (May to August), which coincide with wild dog denning season which could restrict their mobility (Creel \& Creel 2002). Such restricted mobility during denning could thus also have influenced our results. However, low carnivore population densities normally result in a low number of camera trap images (York et al. 2001), which could explain why no wild dog were detected outside Lapalala. This is because wild dogs are rarely tolerated in farming areas (Lindsey et al. 2005a; Gusset et al. 2008b, 2009) and could thus occur at very low densities (Lindsey et al. 2004, 2005a).

Our data highlight that wild dogs still manage to persist on private land in the Waterberg, although probably at low densities. Therefore wild dog conservation efforts should be directed toward actions that increase farmer tolerance (Lindsey et al. 2005a; Gusset et al. 2009). Such programmes have been found to be effective as in Namibia, where farmers have reduced the killing of cheetahs (Acinonyx jubatus) that occur on their land (Marker et al. 2003). Conservation of wild dogs on private land can be motivated by the additional revenue from ecotourism (Lindsey et al. 2005b; Gusset et al. 2008b).

Funding for the initial camera trapping project was received from IFS grant $\mathrm{nr}$. D/4984-1, Wild Foundation grant no. 2008-011, Wilson Foundation and the University of Pretoria. L.H.S. was supported by National Research Foundation (NRF) grant no. 74819. R.R. and M.J.S. were supported by the University of Pretoria and M.J.S. also by the DST-NRF Centre of Excellence Centre for Invasion Biology. We thank one anonymous referee, Marcus Gusset, and Gus Mills for their valuable comments and suggestions which greatly improved the manuscript.

\section{REFERENCES}

AKÇAKAYA, H.R., MILLS, G. \& DONCASTER, C.P. 2007. The role of metapopulations in conservation. In: D.W. Macdonald \& K. Service (Eds), Key topics in conservation biology. Blackwell Publishing, Oxford.

CREEL, S.R. \& CREEL, N.M. 1995. Communal hunting and pack size in African wild dogs, Lycaon pictus. Anim. Behav. 50: 1325-1339.

CREEL, S. \& CREEL, N.M. 2002. The African wild dog: behavior, ecology, and conservation. Princeton University Press, Princeton.

DAVIES-MOSTERT, H.T., MILLS, M.G.L. \& MACDONALD, D.W. 2009. A critical assessment of South Africa's managed metapopulation recovery strategy for African 
wild dogs. In: M.W. Hayward \& M.J. Somers (Eds), Reintroduction of top-order predators. Wiley-Blackwell, Oxford.

FRIEDMANN, Y. \& DALY, B. 2004. Red Data book of the mammals of South Africa: a conservation assessment. CBSG Southern Africa, Conservation Breeding Specialist Group (SS/IUCN) \& Endangered Wildlife Trust, Johannesburg.

GUSSET, M., RYAN, S.J., HOFMEYR, M., VAN DYK, G., DAVIES-MOSTERT, H.T., GRAF, J.A., OWEN, C., SZYKMAN, M., MACDONALD, D.W., MONFORT, S.L., WILDT, D.E., MADDOCK, A.H., MILLS, M.G.L., SLOTOW, R. \& SOMERS, M.J. 2008a. Efforts going to the dogs? Evaluating attempts to re-introduce endangered wild dogs in South Africa. J. Appl. Ecol. 45: 100-108.

GUSSET, M., MADDOCK, A.H., GUNTHER, G.J., SZYKMAN, M., SLOTOW, R \& SOMERS, M.J. 2008b. Conflicting human interests over the re-introduction of endangered wild dogs in South Africa. Biodivers. Conserv. 17: 83-101.

GUSSET, M., SWARNER, M.J., MPONWANE, L., KELETILE, K. \& McNUTT, J.W. 2009. Human-wildlife conflict in northern Botswana: livestock predation by endangered African wild dog Lycaon pictus and other carnivores. Oryx 43: 67-72.

HAYWARD, M.W., O'BRIEN, J., HOFMEYR, M. \& KERLEY, G.I.H.2006. Prey preferences of the African wild dog Lycon pictus (Canidae: Carnivora): ecological requirements for conservation. J. Mammal. 87: 1122-1131.

KARANTH, K.U. 1995. Estimating tiger populations from camera-trap data using capture-recapture models. Biol. Conserv. 71: 333-338.

KARANTH, K.U. \& SUNQUIST, M.E. 1995. Prey selection by tiger, leopard \& dhole in tropical forests. J. Afr. Ecol. 64: 439-450.

KEOGH, H.J. 1983. A photographic reference system of the microstructure of the hair of southern African bovids. S. Afr. J. Wildl. Res. 13: 89-132.

LINDSEY, P.A., DU TOIT, J.T. \& MILLS, M.G.L. 2004. The distribution and population status of African wild dogs (Lycaon pictus) outside protected areas in South Africa. S. Afr. J. Wildl. Res. 34: 143-151.

LINDSEY, P.A., DU TOIT, J.T. \& MILLS, M.G.L. 2005a. Attitudes of ranchers towards African wild dogs Lycaon pictus: conservation implications on private land. Biol. Conserv. 125: 113-121.

LINDSEY, P.A., ALEXANDER, R., DU TOIT, J.T. \& MILLS, M.G.L. 2005b. The potential contribution of ecotourism to African wild dog Lycaon pictus conservation in South Africa. Biol. Conserv. 123: 339-348.

LINDSEY, P.A., HAVEMANN, C.P., LINES, R., PALAZY, L., PRICE, A.E., RETIEF, T.A., RHEBERGEN, T. \& VAN DER WAAL, C. 2013. Determinants of persistence and tolerance of carnivores on Namibian ranches: Implications for conservation on southern African private lands. PloS ONE 8: e52458.

MARKER, L.L., MILLS, M.G.L. \& MACDONALD, D.W. 2003. Factors influencing perceptions of conflict and tolerance toward cheetahs on Namibian farmlands. Conserv. Biol. 17: 1290-1298.
MBIZAH, M.M., MARINO, J. \& GROOM, R.J. 2012. Diet of four sympatric carnivores in Savé Valley Conservancy, Zimbabwe: implications for conservation of the African wild dog (Lycaon pictus). S. Afr. J. Wild. Res. 42: 94-103.

MUCINA, L. \& RUTHERFORD, M.C. (Eds) 2006. The vegetation of South Africa, Lesotho and Swaziland. Sterlitzia 19. South African National Biodiversity Institute, Pretoria.

RAMAKRISHNAN, U., COSS, R.G. \& PELKEY, N.W. 1999. Tiger decline caused by the reduction of large ungulate prey: evidence from a study of leopard diets in southern India. Biol. Conserv. 89: 113-120.

PERRIN, M.R. \& CAMPBELL, B.S. 1980. Key to the mammals of the Andries Vosloo Kudu Reserve (Eastern Cape), based on their hair morphology, for use in predator scat analysis. S. Afr. J. Wildl. Res. 10: $1-14$.

POLE, A., GORDON, I.J., GORMAN, M.L. \& MACASKILL, M. 2004. Prey selection by African wild dogs (Lycaon pictus) in southern Zimbabwe. J. Zool., Lond. 262: 207-215.

SOMERS, M.J., GRAF, J.A., SZYKMAN, M., SLOTOW, R. \& GUSSET, M. 2008. Dynamics of a small re-introduced population of wild dogs over 25 years: Allee effects and the implications of sociality for endangered species' recovery. Oecologia 158: 239-247.

TREVES, A., MWIMA, P., PLUMPTRE, A.J. \& ISOKE, S. 2010. Camera-trapping forest-woodland wildlife of western Uganda reveals how gregariousness biases estimates of relative abundance and distribution. Biol. Conserv. 143: 521-528.

TOBLER, M.W. 2007. Camera base version. 1.3 http://www.atrium-biodiversity.org/tools/camerabase / Accessed 29 June 2012.

WOODROFFE, R., McNUTT, J.W. \& MILLS, M.G.L. 2004. The African wild dog. In: C. Sillero \& D.W Macdonald (Eds), Wild canids: status survey and conservation action plan (pp. 174-183). IUCN, Gland.

WOODROFFE, R., LINDSEY, P., ROMAÑACH, S. STEIN, A. \& OLE RANAH, S.M.K 2005. Livestock predation by endangered African wild dogs (Lycaon pictus) in northern Kenya. Biol. Conserv. 124: 225234.

WOODROFFE, R., DAVIES-MOSTERT, H. GINSBERG, J., GRAF, J. LEIGH, K. McCREERY, K. MILLS, M.G.L., POLE, A., RASMUSSEN, G., ROBBINS, R., SOMERS, M. \& SZYKMAN, M. 2007. Rates and causes of mortality in endangered African wild dogs Lycaon pictus: lessons for management and monitoring. Oryx 41(2): 215-223.

WOODROFFE, R. \& SILLERO-ZUBIRI, C. 2012. Lycaon pictus. In: IUCN 2012. IUCN Red List of Threatened Species. Version 2012.2. Online at: www.iucnredlist. org (downloaded on 21 January 2013).

YORK, E.C., MORUZZI, T.L., FULLER, T.K., ORGAN, J.F., SAUVAJOT, R.M. \& DEGRAAF, R.M. 2001. Description and evaluation of a remote camera and triggering system to monitor carnivores. Wildl. Soc. Bull. 29: 1228-1237. 